\title{
STUDI IDENTIFIKASI DAN PREVALENSI ENDOPARASIT PADA SALURAN PENCERNAAN IKAN KERAPU TIKUS (Cromileptes altivelis) DI KERAMBA JARING APUNG UNIT PENGELOLA BUDIDAYA LAUT SITUBONDO, JAWA TIMUR
}

\author{
PREVALENCE STUDY AND IDENTIFICATION OF ENDOPARASITES ON HUMPBACK \\ GROUPER GASTROINTESTINAL (Cromileptes altivelis) IN FLOATING NET CAGE MARINE \\ CULTURE MANAGEMENT UNIT SITUBONDO, EAST JAVA
}

\author{
Mohammad Faizal Ulkhaq, Kismiyati dan Rahayu Kusdarwati \\ Fakultas Perikanan dan Kelautan Universitas Airlangga \\ Kampus C Mulyorejo - Surabaya, 60115 Telp. 031-5911451
}

\begin{abstract}
Humpback grouper (Cromileptes altivelis) or also known as polkadot grouper is one of the excellent fish commodities in Indonesia which has trading value reached \$90-150/kg. As a consumed fish, humpback grouper are needed for beverage at luxuries restaurant and hotel in the world. As major export commodities in Indonesia, since the 1990's the techniques of grouper cultivation in float net rats are enhanced to fulfill international market demand. Humpback grouper fish cultivation techniques in float net cages cannot be separated from the problems in any cultivate activities, one of the causes is a disease and one of the diseases that rushed humpback grouper is parasite. The disadvantages that caused by the parasite is fish' weight loss.

The purpose of this study is to determine the types of endoparasites that attacked the digestive system of humpback grouper (Cromileptes altivelis) in float net cages and also to discuss the prevalences of endoparasites that attack the digestive of humpback grouper (Cromileptes altivelis) in float net cages.

The method of this research is descriptive. The sampling was done in once for 60 fishes with the length range of fish is around $15-20 \mathrm{~cm}$ and 4 months old from the float net. The number of each fishes samples that were taken 5-10\% from the total of population, where the number of humpback grouper populations in each raft float net are 200 fishes. The main parameters that observed in this study were endoparasites identification species that attack the digestive system of humpback grouper (Cromileptes altivelis) in float net cages and the prevalence rates for each endoparasites. The supporting parameters in this study were the water quality in float net cages which includes temperature, $\mathrm{pH}$ and salinity are measured during the sample taken.

The results showed that 60 samples taken from four float nets 6 fishes were positive infected endoparasitic of trematodes and nematodes, besides 4 fishes are positive infected worms Echinostoma which belong to the class of Trematodes and 2 fishes infected worms Camallanus carangis that belongs to the class Nematoda. The prevalence values for each of the worm are $6.67 \%$ for Echinostoma and $3.33 \%$ for Camallanus carangis. The research concern the identification and prevalence of endoparasites in Humpback grouper at hatchery is needed to early finding out the attack of endoparasites and to break the flow of endoparasitic spreading.
\end{abstract}

Keywords : Identification, Endoparasites, Cromileptes altivelis, Floating Net Cage

\section{Pendahuluan}

Ikan kerapu tikus (Cromileptes altivelis) atau disebut juga ikan kerapu bebek merupakan salah satu primadona komoditas perikanan di Indonesia yang memiliki nilai jual mencapai harga US \$ 90-150/kg (Melianawati dkk., 2010). Sebagai ikan konsumsi, ikan kerapu tikus banyak dibutuhkan untuk hidangan restoran dan hotel mewah di dunia. (Zulkifli dkk., 2000). Sebagai komoditas ekspor utama di Indonesia, sejak tahun 1990-an mulai dikembangkan teknik budidaya ikan kerapu tikus dalam karamba jaring apung untuk memenuhi permintaan pasar internasional yang semakin meningkat (Asaad dkk., 2010). Teknik budidaya ikan kerapu tikus di karamba jaring apung tidak dapat terlepas dari masalah umum dalam setiap kegiatan budidaya, salah satunya adalah masalah penyakit dan penyakit yang menyerang ikan kerapu tikus, salah satunya disebabkan oleh parasit.

Parasit merupakan organisme yang hidup pada atau di dalam organisme lain dan mengambil makanan dari organisme yang ditumpanginya untuk berkembang biak (Subekti dan Mahasri, 2010). Berdasarkan habitatnya, 
parasit dalam tubuh ikan dibagi menjadi dua yaitu ektoparasit (parasit yang menyerang bagian luar tubuh ikan, misalnya pada insang, sirip dan kulit), dan endoparasit (parasit yang menyerang bagian dalam tubuh ikan, misalnya usus, ginjal dan hati) (Balai Karantina Ikan Batam, 2007).

Keberadaan endoparasit dapat menyebabkan kematian pada populasi inang dan konsekuensinya dapat menyebabkan kerugian besar bagi industri perikanan. Infeksi endoparasit dapat menyebabkan dampak yang dapat merugikan secara ekonomi, yaitu ikan kehilangan berat badan, penolakan oleh konsumen karena perubahan patologi pada inang, penurunan fekunditas ikan dan penurunan jumlah dalam penetasan ikan dan larva (Anshary, 2008).

Perkembangan endoparasit dalam tubuh ikan dipengaruhi oleh beberapa faktor lingkungan, diantaranya suhu dan kandungan bahan kimia suatu perairan (Hassan, 2008). Selain itu, adanya organisme invertebrata yang hidup di sekitar karamba jaring apung juga menjadi faktor penyebaran endoparasit pada ikan, karena organisme tersebut dapat berperan sebagai inang perantara dari beberapa spesies endoparasit (Ruckert et al., 2009).

Salah satu kerugian yang ditimbulkan oleh serangan parasit adalah penurunan berat badan ikan yang berhubungan erat dengan adanya endoparasit pada saluran pencernaan ikan sehingga ikan mengalami penurunan nafsu makan. Untuk itu, perlu dilakukan penelitian untuk mengetahui jenis endoparasit yang teridentifikasi pada saluran pencernaan ikan kerapu tikus dan tingkat prevalensinya yang digunakan sebagai data acuan untuk memutus alur distribusi dan penyebaran endoparasit pada ikan kerapu tikus (Cromileptes altivelis).

\section{Metodologi}

Tempat dan Waktu Pelaksanaan

Pengambilan sampel ikan kerapu tikus dilaksanakan di Karamba Jaring Apung, Unit Pengelola Budidaya Laut, Situbondo; Pembedahan sampel ikan kerapu tikus dilakukan di Balai Budidaya Air Payau, Situbondo; Pemeriksaan sampel ikan kerapu tikus dan identifikasi endoparasit dilakukan di Laboratorium Pendidikan Fakultas Perikanan dan Kelautan Universitas Airlangga, Surabaya; dan Pewarnaan endoparasit dilakukan di Laboratorium Parasitologi, Fakultas Kedokteran Hewan Universitas Airlangga, Surabaya pada tanggal 16 Januari-13 Februari 2012.
Materi Penelitian

Peralatan untuk pengambilan sampel.

Peralatan yang digunakan untuk mengambil sampel yaitu serok, seser, ember plastik, baskom, kantong plastik.

Peralatan untuk identifikasi endoparasit

Peralatan yang digunakan untuk proses identifikasi endoparasit yaitu mikroskop, luv, pisau bedah (scalpel), gunting bedah, pinset, object glass, cover glass, kain kasa, pipet, mesin sentrifuge, dan tabung sentrifuge. Peralatan untuk pengukuran kualitas air meliputi: $\mathrm{pH}$ paper untuk pengukuran $\mathrm{pH}$, refraktometer untuk pengukuran salinitas, dan termometer untuk pengukuran suhu.

\section{Bahan Penelitian}

Bahan yang diperlukan untuk proses identifikasi endoparasit adalah ikan kerapu tikus sebanyak 60 ekor dengan ukuran panjang 15-20 $\mathrm{cm}$ dengan umur empat bulan yang diambil dari empat petakan karamba jaring apung milik Unit Pengelola Budidaya Laut, Situbondo. Bahan lain yang diperlukan untuk proses identifikasi dan pewarnaan yaitu larutan $\mathrm{NaCl}$ jenuh, alkohol gliserin 5\%, $\mathrm{NaCl}$ fisiologis, alkohol $70 \%, \mathrm{HCl}, \mathrm{NaHCO}_{3}$, alkohol $85 \%$, alkohol 95\%, larutan Hung's I dan larutan Hung's II.

Penelitian ini menggunakan metode survey melalui pengambilan sampel pada lokasi secara langsung untuk mengidentifikasi jenis endoparasit pada ikan kerapu tikus (Cromileptes altivelis). Lokasi pengambilan sampel ikan ditentukan dengan cara sengaja atau dengan metode purposive sampling (Bunga, 2008). Metode pengambilan sampel dilakukan secara acak (random sampling) terhadap ikan dari karamba jaring apung di Unit Pengelola Budidaya Laut, Situbondo.

a. Pengambilan sampel

Pengambilan sampel dilakukan sekali sebanyak 60 ekor dengan kisaran panjang tubuh ikan antara 15-20 cm dengan umur 4 bulan dari empat petakan karamba jaring apung dengan ukuran $3 \times 3 \times 3 \mathrm{~m}$. Perhitungan jumlah sampel yang diambil mengacu pada Stasiun Karantina Ikan Kelas I Hang Nadim Batam (2010) yaitu jumlah masing-masing sampel ikan yang diambil sebesar 5-10\% dari jumlah total populasi ikan, dimana jumlah populasi ikan kerapu tikus di setiap rakit karamba jaring apung masing-masing 200 ekor. Sampel dimasukkan ke dalam kantong plastik yang telah diisi air dan diberi oksigen lalu dibawa ke Laboratorium Kesehatan Lingkungan Balai Budidaya Air Payau Situbondo, kemudian ditampung dalam akuarium dan diaerasi.

b. Pemeriksaan Sampel dan Identifikasi Parasit 
Sampel diambil satu persatu dari akuarium lalu diletakkan di atas nampan, mematikan saraf otaknya dengan menusukkan jarum pada kepala ikan kemudian diukur panjangnya. Bagian anal ikan dibedah dengan gunting mengarah ke anterior tubuh sampai pada bagian sirip ventral, kemudian digunting ke arah dorsal ikan sampai pada bagian gurat sisi lalu digunting mengarah pada bagian anal ikan. Saluran pencernaan diambil kemudian dimasukkan ke dalam pot plastik yang telah berisi alkohol $70 \%$ dan dimasukkan dalam kotak sterofoam.

Identifikasi endoparasit dilakukan dengan memeriksa sampel dalam pot plastik satu-persatu dengan cara membuka usus dan mengamati keadaan mukosa usus. Feses dikeluarkan dan ditampung dalam object glass atau cawan petri ditetesi air kemudian diamati di bawah mikroskop dengan pembesaran 100x dan 400x (Stasiun Karantina Ikan Kelas I Hang Nadim Batam, 2010). Identifikasi mengacu pada Souslby, (1986), Noble and Noble, (1989), Levine, (1989) untuk cacing Echinostoma dan Rigby et al, (1998), dan Moravec et al, (2006) untuk cacing Camallanus carangis.

Apabila terbukti positif, sampel disendirikan, kemudian endoparasit diambil dan dilakukan pewarnaan, sedangkan apabila terbukti negatif, pemeriksaan sampel dilanjutkan untuk memeriksa telur cacing dengan metode sedimentasi dan pengapungan. Setelah selesai dilakukan pewarnaan, endoparasit diidentifikasi dan didokumentasikan.

c. Pewarnaan Endoparasit

Pewarnaan endoparasit menggunakan metode Semichen-Acetic Carmine yang mengacu pada Kuhlmann (2006), yaitu dengan cara: Cacing dicuci dengan larutan PZ lalu difiksir diantara 2 object glass dan ikat kedua ujungnya dengan benang kemudian dimasukkan dalam alkohol gliserin 5\% selama 24 jam. Setelah itu, cacing dimasukkan dalam alkohol $70 \%$ selama 5 menit, kemudian cacing dipindahkan dalam larutan carmine yang sudah diencerkan dengan alkohol 70\% dengan perbandingan 1:2, dibiarkan selama 8 jam. Cacing dilepas dari object glass dan dipindahkan dalam larutan alkohol asam (alkohol 70\% $+\mathrm{HCl}$ ), selama 2 menit, larutan alkohol basa selama 20 menit (alkohol 70\% + $\mathrm{NaHCO}_{3}$ ), kemudian dilakukan dehidrasi bertingkat dengan alkohol $70 \%$ selama 5 menit, alkohol $85 \%$ selama 5 menit dan alkohol $95 \%$ selama 5 menit. Selanjutnya, dilakukan mounting dalam larutan Hung's I selama 20 menit, kemudian diletakkan pada object glass yang bersih, larutan Hung's II diteteskan di atas cacing tersebut, kemudian ditutup dengan cover glass.

d. Pemeriksaan telur cacing

Menurut Soedarto (2008), pemeriksaan telur cacing dilakukan dengan metode konsentrasi yang dibagi menjadi dua, yaitu :

1. Metode Sedimentasi

Cara kerja dalam metode pemusingan sederhana yaitu : Sejumlah feses dicampur dengan air sebanyak 10x volume feses lalu diaduk sampai tercampur. Campuran feses disaring dengan 2 lapis kain kasa, lalu dimasukkan ke dalam tabung pemusing (centrifuge tube) dan dipusingkan (centrifuge) selama 1-2 menit dengan kecepatan 1500-3000 rpm. Setelah itu, larutan permukaan (supernatan) dibuang dan diganti dengan air, lalu diaduk sampai tercampur dan dipusingkan (centrifuge) kembali dengan kecepatan 15003000 rpm selama 1-2 menit. Larutan permukaan (supernatan) dibuang dan endapan diperiksa di bawah mikroskop dengan perbesaran 100x dan 400x.

2. Metode Pengapungan

Metode ini dilakukan secara langsung dengan mencampur feses dengan larutan pengapung. Larutan pengapung yang digunakan adalah larutan jenuh $\mathrm{NaCl}$. Cara kerja dalam metode ini yaitu: sejumlah feses dicampur dengan air sebanyak 10x volume feses lalu diaduk sampai tercampur. Campuran feses disaring dengan 2 lapis kain kasa, lalu dimasukkan ke dalam tabung pemusing (centrifuge tube) dan dipusingkan (centrifuge) selama 1-2 menit dengan kecepatan 1500-3000 rpm. Setelah itu, larutan permukaan (supernatan) dibuang dan diganti dengan air, lalu diaduk sampai tercampur dan dipusingkan (centrifuge) kembali dengan kecepatan 15003000 rpm selama 1-2 menit. Larutan permukaan (supernatan) dibuang dan endapan dicampur dengan larutan $\mathrm{NaCl}$ jenuh lalu diaduk sampai tercampur dan dipusingkan (centrifuge) kembali dengan kecepatan 1500 rpm selama 1-2 menit. Hasil pemusingan ditambahkan larutan jenuh $\mathrm{NaCl}$ hingga permukaan larutan mendekati mulut tabung lalu ditutup dengan gelas penutup (cover glass) pada mulut tabung dan ditunggu selama 5 menit. Cover glass diambil dan diletakkan diatas object glass kemudian diperiksa dibawah mikroskop dengan perbesaran 100x dan 400x.

Parameter yang utama yang diamati dalam penelitian ini adalah jenis endoparasit yang menyerang saluran pencernaan ikan kerapu tikus (Cromileptes altivelis) di karamba jaring apung dan tingkat prevalensi endoparasit. 
Prevalensi serangan endoparasit dihitung sesuai dengan Bush et al (1997) dalam Bunga, (2008) dengan rumus sebagai berikut:

$$
\text { Prevalensi }=\underline{\mathrm{N} \times 100 \%}
$$

Dimana :

Prevalensi : Persentase ikan yang terserang penyakit (\%)

$\mathrm{N} \quad$ : Jumlah sampel ikan (inang) yang terinfeksi parasit (ekor)

$\mathrm{n}$ : Jumlah sampel ikan (inang) yang diamati (ekor)

Sedangkan parameter penunjang dalam penelitian ini yaitu nilai kualitas air pada karamba jaring apung yang meliputi suhu, $\mathrm{pH}$ dan salinitas yang diukur selama kegiatan pengambilan sampel.

\section{Analisis Data}

Data hasil identifikasi endoparasit yang menyerang ikan kerapu tikus dianalisis secara deskriptif dan disajikan dalam bentuk gambar dan tabel. Nilai prevalensi dihitung untuk setiap spesies parasit (Steel and Torrie, 1993).

\section{Hasil dan Pembahasan}

Identifikasi Endoparasit

Hasil identifikasi endoparasit pada saluran pencernaan ikan kerapu tikus dapat dilihat pada Tabel 1 .
Tabel 1. Hasil Identifikasi Endoparasit pada Saluran Pencernaan Ikan Kerapu Tikus

\begin{tabular}{|c|c|c|}
\hline No. & Lokasi & $\begin{array}{c}\text { Jenis Endoparasit } \\
\text { yang ditemukan }\end{array}$ \\
\hline 1. & Karamba 2 & Camallanus carangis \\
2. & Karamba 3 & Echinostoma \\
\hline
\end{tabular}

Hasil identifikasi endoparasit pada saluran pencernaan ikan kerapu tikus ditemukan 2 spesies cacing yaitu: Camallanus carangis yang ditemukan pada lokasi karamba 2 dan Echinostoma yang ditemukan pada ikan di lokasi karamba 3.

Cacing Camallanus carangis dapat diidentifikasi dari bentuk bucal capsule pada bagian anterior tubuh untuk menempel dan mengambil makanan dari inangnya. Hal ini sesuai dengan pernyataan Untergasser, (1989) dalam Adji, (2008) yaitu Cacing parasitik ini memiliki bucal capsule yang dilapisi kutikula yang tebal dan sepasang lekukan pada bucal capsule. Bentuk seperti ini akan membuat cacing ini dapat memegang dengan kuat ke dinding usus dan tidak dapat lepas.

Cacing Echinostoma dapat diidentifikasi karena memiliki oral sucker dan ventral sucker yang saling berdekatan dengan ukuran yang berbeda. Pernyataan ini sesuai dengan pendapat Noble and Noble (1989) yang menyatakan bahwa cacing Echinostoma

Tabel 2. Hasil Penghitungan Prevalensi Endoparasit Saluran Pencernaan Ikan Kerapu Tikus

\begin{tabular}{|c|c|c|c|c|}
\hline \multirow{2}{*}{ Lokasi } & \multirow{2}{*}{$\begin{array}{c}\text { Jumlah Sampel yang } \\
\text { Diambil (ekor) }\end{array}$} & \multicolumn{2}{|c|}{$\begin{array}{c}\text { Jumlah Ikan yang } \\
\text { terinfeksi (ekor) }\end{array}$} & \multirow{2}{*}{ Prevalensi (\%) } \\
\cline { 3 - 4 } & 15 & + & - & 0 \\
Karamba 1 & 15 & 2 & 13 & 13,33 \\
Karamba 2 & 15 & 4 & 11 & 26,67 \\
Karamba 3 & 15 & 0 & 15 & 0 \\
\hline
\end{tabular}

Tabel 3. Hasil pengukuran kualitas air

\begin{tabular}{|c|c|c|c|c|c|}
\hline No & Parameter & KJA 1 & KJA 2 & KJA 3 & KJA 4 \\
\hline 1. & Suhu & $31^{\circ} \mathrm{C}$ & $31^{\circ} \mathrm{C}$ & $30^{\circ} \mathrm{C}$ & $31^{\circ} \mathrm{C}$ \\
2. & Salinitas & $35 \mathrm{ppt}$ & $35 \mathrm{ppt}$ & $34 \mathrm{ppt}$ & $34 \mathrm{ppt}$ \\
3. & $\mathrm{pH}$ & 7 & 7 & 7 & 7 \\
\hline
\end{tabular}


merupakan cacing yang berbentuk memanjang dengan dua alat penghisap yang saling berdekatan. Alat penghisap perut (ventral sucker) berukuran lebih besar dibandingkan alat penghisap mulut (oral sucker). Selain itu, cacing Echinostoma juga memiliki ovarium dan sepasang testis berbentuk oval dan terletak tandem (Birmani et al., 2008).

\section{Prevalensi Endoparasit}

Prevalensi merupakan persentase ikan yang terinfeksi dibandingkan dengan seluruh ikan sampel yang diperiksa (Stasiun Karantina Ikan I Hang Nadim, 2010). Hasil penelitian menunjukkan bahwa tingkat prevalensi endoparasit ikan kerapu tikus pada tiap petak karamba jaring apung berbeda-beda. Data hasil penghitungan prevalensi endoparasit dapat dilihat pada Tabel 2 .

Nilai prevalensi endoparasit pada ikan kerapu tikus di karamba jaring apung yaitu $13,33 \%$ untuk Camallanus carangis dan 26,67\% untuk Echinostoma. Karamba 1 dan 4 tidak ditemukan ikan yang terinfeksi endoparasit, sehingga prevalensi masing-masing karamba adalah $0 \%$. Karamba 2 dengan jumlah ikan yang terinfeksi endoparasit jenis Camallanus carangis sejumlah 2 ekor, sehingga nilai prevalensinya sebesar $13,33 \%$. Karamba 3 dengan jumlah ikan yang terinfeksi endoparasit jenis Echinostoma sejumlah 4 ekor sehingga nilai prevalensinya sebesar $26,67 \%$. Secara umum, prevalensi endoparasit yang menyerang ikan kerapu tikus di karamba jaring apung yaitu $10 \%$

\section{Nilai Kualitas Air}

Hasil pengukuran kualitas air pada lokasi pengambilan sampel dapat dilihat pada Tabel 3.

Hasil pengukuran kualitas air pada lokasi pengambilan sampel menunjukkan kondisi perairan masing-masing lokasi karamba masih dalam keadaan normal. Data pengukuran kualitas air menunjukkan nilai kisaran kualitas air yaitu: suhu $30-31^{\circ} \mathrm{C}$, salinitas $34-35 \mathrm{ppt}$, dan $\mathrm{pH} 7$.

Endoparasit adalah parasit yang menyerang organ dalam tubuh inangnya. Endoparasit dapat protozoa, misalnya Trypanosoma dan Eimeria, dan endoparasit cacing, seperti Anisakis simplex dan Diphyllobotrium latum (Diba, 2009).

Endoparasit yang ditemukan pada penelitian ini termasuk dalam phylum Nemathelminthes dan Platyhelminthes. Cacing Camallanus carangis termasuk dalam Phylum Nemathelminthes, Kelas Nematoda, Ordo
Camallanoidea, Famili Camallanidae, Genus Camallanus, dan spesies Camallanus carangis (Rigby et al., 1998).

Hasil pewarnaan menunjukkan bahwa cacing Camallanus carangis memiliki alat penempel pada bagian anterior tubuh. Seperti dikemukakan oleh Moravec et al, (2006), organ khas yang dimiliki oleh cacing Camallanus yaitu adanya bucal capsule yang digunakan untuk menempel pada organ inang dan mengambil makanan dari inang. Cacing Camallanus carangis jantan memiliki panjang 4,198-11,092 mm dan lebar 1,21-2,8 mm. Bucal capsule memiliki panjang 1,19-1,52 mm dan lebar 1,18-1,59 mm. Cacing Camallanus carangis betina memiliki panjang 6,788-7,548 $\mathrm{mm}$ dan lebar 2,54-2,82 mm. Bucal capsule memiliki panjang 1,62-1,73 $\mathrm{mm}$ dan lebar 1,621,94 mm (Rigby, et al., 1998).

Cacing parasitik ini memiliki bucal capsule yang dilapisi kutikula yang tebal dan sepasang lekukan pada bucal capsule. Mulutnya seperti penjepit yang kuat, berbingkai yang dikelilingi oleh buku-buku semacam tanduk. Bentuk seperti ini akan membuat cacing ini dapat memegang dengan kuat ke dinding usus dan tidak dapat lepas. Tempat berkaitnya cacing ini pada usus dapat terjadi pendarahan. Mulut sampai esofagus memiliki dinding otot yang tebal, biasanya esofagus dilapisi kutikula (Untergasser, 1989 dalam Adji, 2008). Gambar Camallanus carangis dapat dilihat pada Gambar 1 .

Cacing Echinostoma termasuk dalam Phylum Platyhelminthes, Kelas Trematoda, Ordo Prosostomata, Family Echinostomatidae, Genus Echinostoma. (Soulsby, 1986). Cacing ini berbentuk pipih dengan panjang 14,21415,885 mm dan lebar 1,499-1,642 mm (Birmani et al., 2008). Cacing ini memiliki karakteristik khas yaitu memiliki 2 alat penghisap (sucker), yaitu penghisap mulut (oral sucker) yang terletak di bagian anterior dan penghisap perut (ventral sucker) yang berukuran lebih besar dari oral sucker. Hal ini sesuai dengan pernyataan Kanev et al., (1995) yaitu Oral sucker berukuran diameter 0,17-0,26 mm dan ventral sucker berukuran diameter 0,45-0,65 mm.

Cacing Echinostoma memiliki duri pada bagian oral sucker dan ventral sucker, ovarium dan sepasang testis berbentuk oval dan terletak tandem. Ovarium berbentuk bulat dengan diameter 0,428-0,571 mm. Testis bagian anterior memiliki ukuran panjang 1,071-1,178 $\mathrm{mm}$ dan lebar 0,285-0,399 mm dan pada testis bagian posterior memiliki panjang 0,999-1,142 $\mathrm{mm}$ dan lebar 0,285-0,371 $\mathrm{mm}$. Jarak antara testis bagian anterior dan posterior yaitu 0,464 - 


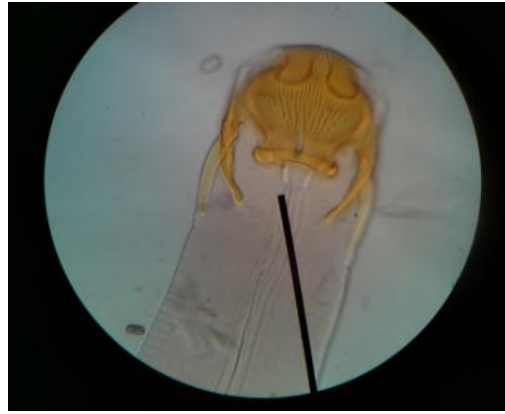

A

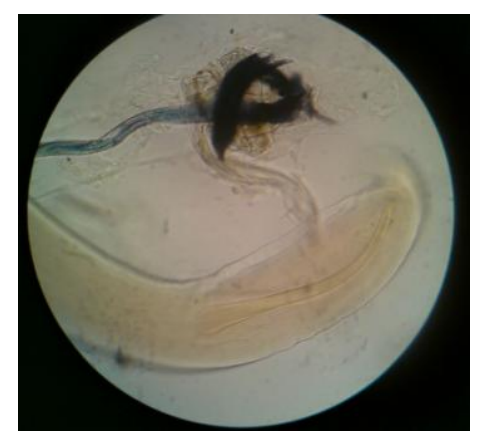

B

Gambar 1. Hasil pewarnaan Camallanus carangis dengan pembesaran 100x.

Keterangan:

a. Bucal capsule pada bagian anterior.

b. Alat kelamin jantan pada bagian posterior.
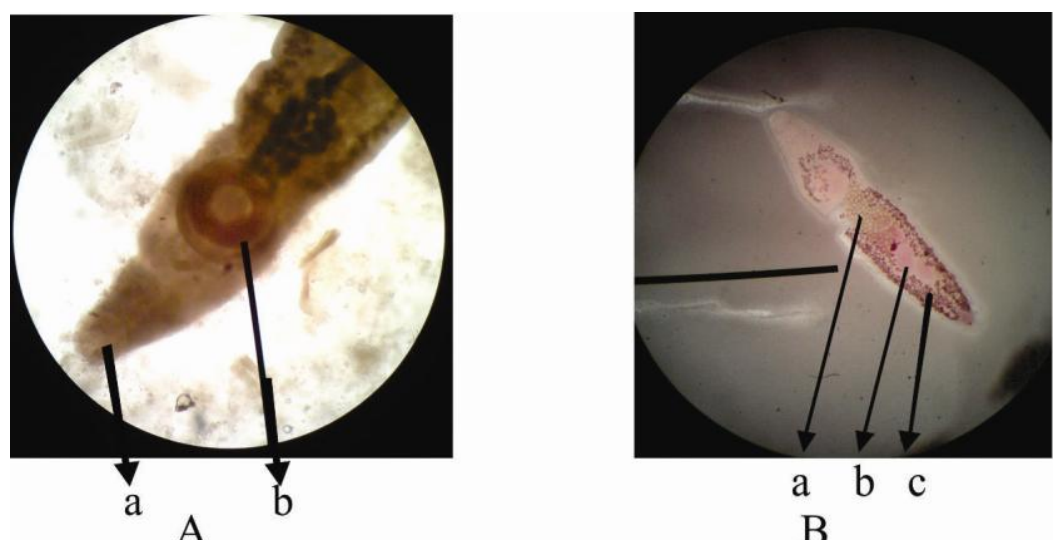

Gambar 2. Echinostoma

Keterangan :

A. Hasil pengamatan natif dengan perbesaran 100x. Bagian anterior dengan Oral sucker (a) dan Ventral sucker (b).

B. Hasil pewarnaan dengan perbesaran 40x. Telur (a), Testis (b), Vitellaria (c).

0,785 mm (Birmani et al., 2008). Gambar cacing Echinostoma dapat dilihat pada Gambar 2 .

Infeksi cacing endoparasit pada ikan tidak menunjukkan gejala klinis yang khas, hal ini terlihat pada ikan sampel yang menunjukkan tingkah laku dan nafsu makan yang normal. Hal ini sesuai dengan pernyataan Sarjito dan Desrina, (2005) yang menyebutkan infeksi cacing endoparasit tidak menunjukkan gejala klinis eksternal yang jelas (misalnya luka pada tubuh atau adanya kista) sehingga tidak terdeteksi dengan cepat, akan tetapi keberadaan cacing ini terlihat jika ikan dibedah dan diamati organ dalamnya. Selain itu, keberadaan cacing endoparasit pada ikan dapat menyebabkan gangguan pertumbuhan pada tingkat infeksi yang tinggi dan tidak menunjukkan gejala pada tingkat infeksi yang rendah (Hassan, 2008)

Ikan yang terinfeksi endoparasit akan menyebabkan penurunan nafsu makan yang kemudian akan berpengaruh terhadap pertumbuhan. Sebagaimana dikemukakan oleh Sarjito dan Desrina (2005) yaitu infeksi endoparasit menyebabkan penurunan fekunditas telur, meningkatkan kerentanan ikan terhadap patogen lain seperti virus dan bakteri serta pertumbuhan yang terhambat.

Hasil penelitian menunjukkan bahwa tingkat prevalensi tiap petak karamba jaring apung berbeda-beda. Petakan karamba pertama dan keempat menunjukkan nilai prevalensi sebesar $0 \%$ yang berarti bahwa sampel ikan yang diambil dari petakan karamba tersebut tidak ada yang terinfeksi endoparasit. Nilai 
prevalensi tersebut menurut William and Bunkley-William, (1996) dalam Adji, (2008) termasuk dalam kategori almost never (tidak pernah). Petakan karamba kedua menunjukkan nilai prevalensi sebesar $13,33 \%$ dan termasuk dalam kategori often (sering) dan petakan karamba ketiga menunjukkan nilai prevalensi sebesar $26,67 \%$ yang termasuk dalam kategori often (sering). Sedangkan secara umum, prevalensi endoparasit yang menyerang ikan kerapu tikus di karamba jaring apung yaitu 10\% dengan kategori often (sering).

Prevalensi endoparasit tertinggi terdapat pada petakan karamba ketiga yaitu sebesar $26,67 \%$ dan berdasarkan penelitian kelompok, pada petakan karamba ketiga juga memiliki prevalensi ektoparasit tertinggi yaitu $53,33 \%$. Hal ini kemungkinan disebabkan karena kondisi jaring yang kotor, sehingga banyak ditempeli oleh hewan liar dari kelas Crustacea dan Molusca serta tumbuhan alga. Hewan liar tersebut dapat berperan sebagai inang perantara beberapa endoparasit, seperti yang dikemukakan oleh Ruckert et al., (2009) yaitu keberadaan endoparasit dalam tubuh ikan juga dipengaruhi oleh adanya organisme invertebrata, misalnya Crustacea dan Molusca di sekitar lokasi budidaya. Organisme tersebut berperan sebagai inang perantara dari beberapa spesies endoparasit. Lafferty, (2011) menyatakan bahwa ikan dapat terinfeksi endoparasit dikarenakan adanya parasit pada pakan yang diberikan baik dalam bentuk telur maupun stadia larva. Selain itu, kondisi lingkungan yang kotor juga menyebabkan ikan menjadi stress yang akhirnya dapat menurunkan sistem imun ikan tersebut. Sebagaimana dikemukakan oleh Yuliartati, (2011) yaitu faktor yang memicu timbulnya stress pada ikan yaitu ketidakseimbangan interaksi faktor biotik (organisme) dan faktor abiotik (lingkungan) yang menyebabkan daya tubuh ikan menurun dan mudah terserang penyakit.

Prevalensi terendah terdapat pada petakan karamba pertama dan keempat yaitu sebesar $0 \%$, dan berdasarkan penelitian kelompok, pada petakan karamba pertama dan keempat juga memiliki prevalensi ektoparasit terendah yaitu masing-masing 26,67\%. Hal ini disebabkan karena kondisi jaring yang lebih bersih, yaitu dibersihkan setiap satu bulan sekali. Sesuai dengan pernyataan Usman, (2011) yaitu pembersihan jaring karamba minimal dilakukan setiap bulan, karena jaring karamba yang kotor merupakan media penempelan parasit dan penyakit serta mengganggu sirkulasi air. Selain itu, rendahnya nilai prevalensi ini disebabkan oleh keadaan endemik suatu parasit, kemampuan adaptasi parasit di tubuh inang, kecocokan inang untuk kelangsungan hidup parasit dan kualitas lingkungan (Diba, 2009).

Nilai kualitas air pada penelitian ini didapatkan kisaran nilai kualitas air yang normal yaitu: suhu $30-31{ }^{\circ} \mathrm{C}$, salinitas $34-35 \mathrm{ppt}$, dan $\mathrm{pH}$ 7. Nilai kualitas air ini merupakan nilai yang optimum untuk budidaya ikan kerapu tikus sebagaimana dinyatakan oleh Kangkan dkk. (2007) yaitu suhu optimal untuk budidaya ikan kerapu tikus yaitu $27-32^{\circ} \mathrm{C}$, salinitas $33-35 \mathrm{ppt}$ dan $\mathrm{pH} 7,6-8,7$.

\section{Kesimpulan}

Berdasarkan hasil penelitian dapat disimpulkan bahwa : Endoparasit yang menyerang saluran pencernaan ikan kerapu tikus (Cromileptes altivelis) di karamba jaring apung Unit Pengelola Budidaya Laut, Situbondo, Jawa Timur adalah Camallanus carangis (Nematoda: Camallanidae) dan Echinostoma (Trematoda: Echinostomatidae).

Prevalensi endoparasit yang menyerang saluran pencernaan ikan kerapu tikus (Cromileptes altivelis) di karamba jaring apung Unit Pengelola Budidaya Laut Situbondo, Jawa Timur adalah $10 \%$, sehingga termasuk dalam kategori often (sering).

Saran yang dapat diberikan penulis yaitu perlu dilakukan manajemen pembersihan jaring yang teratur dan berkala agar kondisi jaring tetap bersih dan mencegah penempelan oleh hama yang merupakan inang perantara dari endoparasit.

\section{Daftar Pustaka}

Adji, A.O.S. 2008. Studi Keragaman Cacing Parasitik pada Saluran Pencernaan Ikan Gurami (Osphronemus gouramy) dan Ikan Tongkol (Euthynnus spp.). Skripsi. Fakultas Kedokteran Hewan. Institut Pertanian Bogor. Bogor. 51 hal.

Anshary, H. 2008. Modul Pembelajaran Berbasis Student Center Learning (SCL) Mata Kuliah Parasitologi Ikan. Lembaga Kajian dan Pengembangan Pendidikan (LKPP). Universitas Hasanuddin. Makassar. 126 hal.

Asaad, A.I.J., Makmur, Rachmansyah, M.C. Undu dan Muawanah. 2010. Analisis Faktor Kondisi Kontinuitas Budidaya Keramba Jaring Apung di Teluk Lampung. Prosiding Forum Inovasi Teknologi Akuakultur. BBRBAP. Maros. 7 hal.

Balai Karantina Ikan Batam. 2007. Laporan Pemantauan HPI/HPIK Tahun 2007. 
Balai Karantina Ikan Batam. Batam. 52 hal.

Birmani, N.A., A.M. Dharejo and M.M. Khan. 2008. Echinostoma atrae, New Spesies (Digenea: Echinostomatidae) in Black Coot Fulica atra (Aves: Rallidae) of Manchhar Lake, Sindh, Pakistan. Journal of Pakistan Zoology 40(5): 379-383.

Bunga, M. 2008. Prevalensi dan Intensitas Serangan Parasit Diplectanum sp. Pada Insang Ikan Kerapu Macan (Epinephelus fuscoguttatus, Forsskal) di Keramba Jaring Apung. Jurnal Ilmu Kelautan dan Perikanan Universitas Hasanuddin 18 (3) : 204-210.

Bunga, M., A. Rantetondok dan H. Anshary. 2009. Tingkat Infeksi, Mikrohabitat dan Patologis Parasit Diplectanum sp. pada Insang Ikan Kerapu Macan (Epinephelus fuscoguttatus, Forsskal) di Keramba Jaring Apung. Jurnal Sains dan Teknologi 9 (2) : 73-80.

Diba, D.F. 2009. Prevalensi dan Intensitas Infestasi Endoparasit Berdasarkan Hasil Analisis Feses Kura-kura Air Tawar (Coura amboinensis) di Perairan Sulawesi Selatan. Tesis. Sekolah Pascasarjana. Institut Pertanian Bogor. Bogor. 47 hal.

Hassan, M. 2008. Parasites of Native and Exotic Freshwater Fishes in the South-West of Western Australia. Thesis. Murdoch University. Perth, Western Australia. 173 hal.

Kanev, I.,V.Dimitrov, V.Radev, B.Fried. 1995. Redescription of Echinostoma jurini (Skvortzov, 1924) with a Discussion of its Identity and Characteristics. Journal Naturhistorisches Musium Wien 97B: 37-53.

Kangkan, A.L., A. Hartoko, Suminto. 2007. Studi Penentuan Lokasi untuk Pengembangan Budidaya Laut Berdasarkan Parameter Fisika, Kimia, dan Biologi di Teluk Kupang, Nusa Tenggara Timur. Jurnal Pasir Laut 3 (1): 76-93.

Kuhlmann, W.F. 2006. Preservation, Staining, and Mounting Parasite Spesiment. http://www.facstaff.unca.com. 17/12/2011. 8 p.

Lafferty, K. 2011. Fish Parasites and Food Webs. International Symposium of Fish Parasites. 26-30 September 2011. Vina del Mar. Chile. 197 p.

Melianawati R., R. Andamari, dan I. Setyadi. 2010. Identifikasi Profil Aktifitas Enzim Pencernaan untuk Optimasi Pemanfatan
Pakan dalam Usaha Budidaya Ikan Kerapu Bebek (Cromileptes altivelis). Badan Penelitian dan Pengembangan Kelautan dan Perikanan. Kementerian Kelautan dan Perikanan. Jakarta. 28 hal.

Moravec, F., J.L. Justine and M.C. Rigby. 2006. Some Camallanid Nematodes from Marine Perciform Fishes Off New Caledonia. Journal Folia Parasitologica 53: 223-239.

Noble, G.A and E.R. Noble. 1989. Parasitologi : Biologi Parasit Hewan. Terjemahan: Wardiarto. Gadjah Mada University Press. Yogyakarta. hal 3-44.

Rigby, M.C., M.L. Adamson, and T.L. Deardorf. 1998. Camallanus carangis Olsen, 1954 (Nematoda: Camallanidae) Reported from French Polynesia and Hawai with a Redescription of the Spesies. Journal of Parasitology 84 (1): 158-162.

Ruckert, S., S.Klimpel, S. Al-Quraishy, H. Mehlhorn, and H.W. Palm. 2009. Transmission of Fish Parasites into Grouper Mariculture (Serranidae: Epinephelus coioides (Hamilton, 1882)) in Lampung Bay, Indonesia. Journal Parasitology Reseach (2009) 104: 523532.

Sarjito dan Desrina. 2005. Analisa Infeksi Cacing Endoparasit pada Ikan Kakap Putih (Lates calcarifer Bloch) dari Perairan Pantai Demak. Laporan Kegiatan Hasil Penelitian Dosen Muda. Fakultas Perikanan dan Ilmu Kelautan. Universitas Diponegoro. Semarang. 18 hal.

Soedarto. 2008. Parasitologi Klinik. Airlangga University Press. Surabaya. hal 8-18.

Soulsby, E.J.L.1986. Helminth, Antropods, and Protozoa of Domesticated Animals. $7^{\text {th }}$ ed. Baillere Tindall. London.

Stasiun Karantina Ikan Kelas I Hang Nadim Batam. 2010. Laporan Pemantauan HPI dan HPIK. Stasiun Karantina Ikan Kelas I Hang Nadim Batam. Batam. 57 hal.

Steel R. G. and Torrie J. H. 1993. Prinsip Prosedur Statistika. Terjemahan Oleh Bambang Sumantri. Gramedia. Jakarta.

Subekti, S. dan G. Mahasri. 2010. Buku Ajar Parasit dan Penyakit Ikan (Trematodiasis dan Cestodiasis). Global Persada Press. Surabaya. 91 hal.

Usman. 2011. Budidaya Ikan dalam Keramba Jaring Apung. Balai Riset Perikanan Budidaya Air Payau Maros, Sulawesi Selatan. 42 hal. 
Yuasa L. dan N. Kei. 2003. Panduan Diagnosa Penyakit Ikan. Balai Budidaya Air Tawar. Jambi. 37 hal.

Yuliartati, E. 2011. Tingkat Serangan Ektoparasit pada Ikan Patin (Pangasius djambal) pada Beberapa Pembudidaya Ikan di Kota Makassar. Skripsi. Program Studi Budidaya Perairan. Jurusan Perikanan. Fakultas Ilmu Kelautan dan Perikanan. Universitas Hasanuddin. Makassar. 65 hal.
Zulkifli, A.K., M. Nasir U., T. Iskandar, Mukhlisuddin, A. Azis, Yulham, Bahrun. 2000. Rakitan Teknologi Budidaya Kerapu dalam Keramba Jaring Apung (KJA). Modul Pembelajaran Universitas Syiah Kuala Banda Aceh. Aceh. 9 hal. 